\title{
Infrações Ambientais e a Reputação do Regulador: Análise em Dados de Painel para o Brasil ^
}

\author{
Júlia Gallego Ziero Uhr \\ Professora - Programa de Pós-Graduação em Organizações e Mercados (PPGOM)/UFPel \\ Endereço: Gomes Carneiro, n 1, $4^{\circ}$ Andar, Campus Porto, Pelotas - RS - Brasil \\ CEP: 96010-610 - E-mail: julia.uhr@ufpel.edu.br
}

\author{
Daniel de Abreu Pereira Uhr \\ Professor - Programa de Pós-Graduação em Organizações e Mercados (PPGOM)/UFPel \\ Endereço: Gomes Carneiro, no 1, $4^{\circ}$ Andar, Campus Porto, Pelotas - RS - Brasil \\ CEP: $96010-610$ - E-mail: daniel.uhr@ufpel.edu.br
}

Recebido em 13 de janeiro de 2013. Aceito em 07 de outubro de 2013.

\begin{abstract}
Resumo
O objetivo deste artigo é testar o papel do regulador no combate a infrações ambientais no Brasil. As principais variáveis explicativas são os valores das multas lavradas no estado (efeito específico) e nos estados vizinhos (efeito spillover), que refletem a reputação do regulador. Este artigo testa ainda o papel complementar dos agentes privados sobre o monitoramento e a aplicação de sanções informais. A fonte de dados compreende, em nível estadual, a quantidade de autos de infração registrados pelo IBAMA e as respectivas multas aplicadas para os anos de 2000 a 2011 . Os resultados obtidos pelo método de Efeitos Fixos demonstram que um aumento no valor das multas aplicadas em um estado e em seus vizinhos gera uma redução no número de autos de infração para anos subsequentes à aplicação da multa.
\end{abstract}

\section{Palavras-Chave}

infrações ambientais, multas, regulação formal, efeitos spillover, painel

\begin{abstract}
The aim of this paper is to test the role of the regulator in combating environmental infractions in Brazil. The main explanatory variables are the values of fines imposed on the state (specific effect) and on surrounding states (spillover effect), which reflect the reputation of the regulator. This paper also examines the complementary role of private agents on monitoring and application of informal sanctions. The data source comprises, at state level, the amount of notices of violation recorded by IBAMA and the related fines for the years 2000 to 2011 . The results obtained by the method of Fixed Effects demonstrate that an increase on the values of fines imposed on a state and its neighbors generates a reduction in the number of notices of infraction for the years following the imposition of a fine.
\end{abstract}

\footnotetext{
- Os autores agradecem as contribuições e sugestões de André Chagas, Bernardo Mueller, José Gustavo Ferres, Tainá Leandro e dos pareceristas anônimos.
} 


\section{Keywords}

environmental infractions, fines, formal regulation, spillover effects, panel data

\section{JEL Classification}

D60, K42, Q50

\section{Introdução}

A regulação ambiental e a aplicação de sanções formais, inclusive as multas, fazem parte da política ambiental de quase todas as nações, não sendo diferente no Brasil. A teoria econômica do crime indica que tal procedimento é importante para combater violações ambientais e a consequente degradação do meio ambiente.

Neste trabalho, nosso objetivo central é testar o papel do regulador no combate a infrações ambientais. Nossa estratégia é ligar as multas impostas e o gasto do governo com controle ambiental ao comportamento subsequente de cumprimento da lei por parte dos agentes econômicos. A principal variável explicativa empregada neste trabalho consiste no valor (magnitude) das multas lavradas, que possui um efeito específico (sobre o estado multado) e um efeito spillover (sobre estados vizinhos). Isso decorre da reputação do regulador: uma multa aplicada sinaliza de forma crível a disposição da autoridade ambiental em aplicar multas em outros estados, amplificando o impacto desse tipo de sanção.

A novidade deste artigo consiste não só em testar a reputação do regulador para o Brasil, mensurando o efeito sobre o estado multado e o efeito sobre os estados vizinhos, mas também a base de dados que foi utilizada. A fonte de dados primária compreende, a nível estadual, a quantidade de autos de infração registrados pelo IBAMA para diversas categorias e os valores das respectivas multas aplicadas para os anos de 2000 a 2011. Esta base de dados jamais foi utilizada em pesquisas no campo da regulação ambiental e da economia do crime, sendo, portanto, fonte de novas evidências para o Brasil. Assim, as análises realizadas com estes dados trazem destaque sobre a efetividade da política ambiental formal (convencional) adotada no Brasil, enfatizando as políticas públicas adotadas. 
Além de testar a influência da reputação do regulador sobre a incidência de infrações ambientais, um objetivo secundário é verificar o papel dos agentes privados (regulação informal). A literatura recente destaca a influência complementar que os consumidores e ONGs têm sobre o monitoramento e sobre a aplicação de sanções indiretas (Uhr, Uhr \& Mueller, 2012). Neste sentido, variáveis que captem as ações dos agentes privados podem afetar a incidência de infrações.

Os resultados encontrados neste trabalho sugerem que a regulação formal, em especial a aplicação de multas, tem um efeito impeditivo importante. De fato, as multas em anos anteriores se mostram significativas para conter o número de infrações nos estados em que foram aplicadas (efeito específico). E, mais importante, as multas aplicadas em estados vizinhos, em anos anteriores, também são significativas para o combate a violações ambientais (efeito spillover). Então, focar somente no efeito impeditivo específico pode subestimar a eficácia das multas como sanções e como forma de prevenção para infrações ambientais futuras no Brasil.

Este artigo esta estruturado da seguinte maneira. A próxima seção apresenta a revisão da literatura empírica sobre violações ambientais, fiscalização e aplicação da lei. A seguir, discutimos o referencial teórico e o modelo de infrações ambientais. $\mathrm{Na}$ seção 4 apresentamos os dados, suas fontes e as hipóteses para o uso de cada variável. O modelo econométrico a ser estimado é apresentando na seção 5 . A seção seguinte apresenta os resultados das estimações e interpretações. A seção 7 conclui o trabalho.

\section{Referencial Empírico}

Esta seção revisa a pesquisa empírica sobre o efeito impeditivo que o monitoramento e a aplicação de sanções têm sobre as violações ambientais, ${ }^{1}$ tanto na sua perspectiva formal (atuação do governo), quanto informal (atuação de setores privados da sociedade).

\footnotetext{
1 Neste trabalho, a não ser quando indicado, os termos "infração", "violação" e "crime" são tratados como sinônimos, uma vez que não existe distinção econômica $a$ priori entre eles. O Código Penal brasileiro define como crime "a infração penal a que a lei comina pena de reclusão ou detenção, quer isoladamente, quer alternativa ou cumulativamente com a pena de multa". Já o dicionário da língua portuguesa define a palavra crime como "infração moral grave; delito".
} 
Almer \& Goeschl (2010) exploram dados em painel (quinze estados alemães e período de dez anos) para estudar o efeito impeditivo da execução criminal sobre ofensas ambientais na Alemanha. As principais contribuições do trabalho são o exame dos dados para comprovar a hipótese de que sanções criminais (como o encarceramento e as multas pesadas) têm sucesso em impedir crimes ambientais e a determinação das contribuições individuais dos diferentes tipos de sanções sobre o efeito impeditivo. As variáveis explicativas utilizadas englobam as taxas de crimes apurados, suspeitos julgados, condenados, presos e multas severas aplicadas, além de uma variável para consciência ambiental (percentual de adeptos do Partido Verde) e a preferência do governo por qualidade ambiental (dummy para partido conservador).

Os autores concluem que as sanções criminais têm um papel impeditivo importante sobre os crimes ambientais. Em particular, os julgamentos públicos têm efeito quantitativo maior sobre a taxa de crimes do que a probabilidade de condenação e a magnitude das multas. Isso seria causado pela perda de reputação que a firma sofre junto aos seus consumidores e acionistas ao ser levada a um julgamento público. Além disso, o trabalho destaca a importância de fatores políticos para entender as variações nos crimes ambientais reportados, já que a variável de consciência ambiental é significante nas análises estatísticas empregadas.

Shimshack \& Ward (2008) argumentam que sanções criminais não só têm um papel impeditivo importante como elas também garantem o cumprimento da legislação acima do esperado. Ou seja, mesmo para aquelas indústrias que apresentam baixas taxas de violações ambientais, um aumento no monitoramento e aplicação da lei faz com que as plantas reduzam suas emissões de poluentes abaixo dos níveis permitidos por lei. Usando dados para firmas da indústria americana de papel, para os anos de 1990 até 2004 em nível mensal, os autores afirmam que firmas com emissões estocásticas e de mais de um poluente enfrentam incerteza quanto às suas emissões e quanto ao padrão regulatório. Assim, as firmas observam a reputação do regulador, ou seja, a quantidade de multas aplicadas recentemente sobre outras firmas no mesmo estado e sobre a própria firma. Quanto maior a credibilidade do regulador, maior a redução nas emissões, mesmo para aquelas firmas que já estão em cumprimento com a legislação. 
Outras variáveis explicativas incluem o número de inspeções, a produção da firma, a adoção de novas tecnologias de produção e os efeitos fixos em relação à planta. Shimshack \& Ward (2008) concluem que o comportamento das firmas em reduzir emissões abaixo do necessário é gerado pelos fatores econômicos expostos acima e não por um comportamento altruísta (pró meio ambiente).

Shimshack \& Ward (2005) estudam o impacto que uma multa marginal tem sobre a taxa de infrações ambientais cometidas, focando na reputação do regulador e nos efeitos transbordamento, ou seja, como uma multa aplicada em uma firma ajuda a reduzir a taxa de infrações ambientais em todo o estado. Usando dados mensais para a indústria americana de papel, para o período 1988 a 1996, os autores procuram determinar "como" e "quanto" as multas influenciam o cumprimento da legislação ambiental. Além das multas, Shimshack \& Ward (2005) consideram o número de inspeções, notificações formais, sanções administrativas e variáveis socioeconômicas como fatores explicativos das violações. Os autores concluem que, na margem, o impacto de uma multa aplicada em uma firma gera uma redução de $2 / 3$ na taxa de violações de todo o estado para o ano subsequente à aplicação da multa. Além disso, o efeito impeditivo sobre outras firmas do estado é tão forte quanto o efeito sobre a firma multada (efeito transbordamento). Assim, os resultados demonstram que a aplicação de uma única multa aumenta a credibilidade do regulador para todas as firmas, amplificando o impacto da multa. Isso sugere que as firmas observam e aprendem com as próprias experiências passadas e as de seus vizinhos. As demais sanções não monetárias não demonstraram efeitos significantes sobre a taxa de violações, levando à conclusão de que um melhoramento substancial na taxa de infrações poderia ser obtido através de um investimento adicional relativamente pequeno com a aplicação das multas.

Earnhart (2004) analisa os fatores regulatórios que moldam o nível de desempenho ambiental de empresas públicas de tratamento de água e esgoto no estado do Kansas, EUA. O objetivo central da autora é determinar a efetividade das intervenções governamentais no desempenho ambiental das firmas. Por "intervenção" Earnhart (2004) define inspeções e políticas de aplicação da lei a nível estadual e federal em duas formas: intervenções reais e a ameaça de intervenção, ou seja, a probabilidade de ser punido se em desacordo com a legislação. 
Para a análise empírica a autora utiliza dados de emissões para os anos 1990-1998, avaliando fatores regulatórios (permissões de poluição, inspeções e demais ações públicas), características da comunidade em que a firma está inserida (população, taxa de desemprego, educação, renda e votos no partido republicano), características da própria firma (capacidade de produção, tecnologia de tratamento de resíduos), entre outras variáveis explicativas. Os resultados de estimação permitem concluir que o efeito impeditivo gerado pela ameaça de intervenção é forte, sendo que a nível federal tanto a ameaça de inspeção como a ameaça de aplicar uma sanção significativamente induzem um melhor desempenho ambiental. Além disso, a real aplicação de sanções em nível estadual e federal, também induz a um melhor desempenho ambiental das firmas.

Anton et al. (2004) estudam a influência de incentivos de mercado sobre a adoção voluntária de sistemas de gestão ambiental, como o padrão ISO 14000, e o efeito destes sobre o desempenho ambiental das empresas. Usando dados das 500 firmas listadas na Standard \& Poors (maiores empresas americanas de capital aberto), para os anos de 1994 e 1995, os autores objetivam, primeiramente, examinar os fatores que determinam a adoção de práticas de gestão ambiental pelas empresas e, em segundo lugar, estabelecer a abrangência do impacto que esses sistemas têm sobre a intensidade de emissões de poluentes tóxicos do ar. Os resultados utilizando regressões quantílicas mostram que as pressões de consumidores e investidores, juntamente com a possibilidade de punição e a escala passada de emissões, são os determinantes mais importantes para a adoção de estratégias de gestão ambiental. Além disso, estas práticas têm impacto negativo significante sobre a intensidade de emissões tóxicas, principalmente entre firmas onde as emissões passadas excedem a média. Os autores também concluem que os fatores que determinam a pró-atividade das firmas não afetam diretamente a quantidade de emissões tóxicas, mas reduzem emissões indiretamente, através de mudanças institucionais no modo de operação das empresas.

Stafford $(2002,2003)$ examina os impactos do aumento das penalidades e do gasto do governo com meio ambiente para a disposição ilegal de resíduos perigosos. Em 1991 a agência de proteção ambiental americana revisou suas políticas de punição para este tipo de resíduos. Tomando esta mudança na legislação como base e usando dados de firmas americanas para o período 1986-1995, a autora pro- 
cura responder se o aumento na penalidade esperada e nos gastos do governo afetou o cumprimento das normas pelas firmas. As variáveis explanatórias englobam aspectos como a natureza e a quantidade de resíduos perigosos produzidos, características da firma, características estaduais e dummies para os anos de transição e pós-mudança na legislação. Os resultados dos trabalhos são consistentes com o modelo de Becker (1968), uma vez que o aumento nas penalidades e nos gastos do governo levou a diminuição das violações, ou seja, a política revisada teve o efeito desejado ao elevar o número de empresas em cumprimento com a legislação de resíduos perigosos.

Afsah et al. (1996) discutem um modelo com múltiplos agentes, no qual o papel do governo como regulador seria complementado pela comunidade e o mercado como monitoradores das violações ambientais. Assim, o desempenho ambiental dos agentes poluidores seria influenciado, por exemplo, por grupos vizinhos a uma firma ou por seus consumidores. Comunidades mais ricas, bem-educadas e organizadas têm muitas maneiras de garantir o cumprimento das normas ambientais.

Onde a regulação formal está presente, as comunidades utilizam o processo político para influenciar o rigor no cumprimento da lei. Onde o papel do governo é ineficiente ou ausente, a "regulação informal" é implementada por grupos comunitários e ONGs. Segundo Afsah et al. (1996, pg. 6) "em países tão distintos quanto China, Brasil, Indonésia e os Estados Unidos, muita da variação no desempenho ambiental das fábricas é explicado por variações inter-comunidades na renda, educação e poder de barganha". Os autores citam que evidências recentes, tanto para os países da OCDE como países em desenvolvimento, têm mostrado que a reputação ambiental das firmas importa e que os lucros e custos destas firmas são afetados pelo julgamento de consumidores, acionistas e fornecedores.

Em artigos anteriores, o foco de estudo estava nos mecanismos de monitoramento e punição disponíveis para as agências regulatórias. Magat e Viscusi (1990) e Laplante e Rilstone (1996) investigaram o impacto de inspeções e a ameaça de inspeções, respectivamente, para as taxas de adequação às normas de poluição da água e emissões de resíduos na indústria de papel americana e canadense. Gray e Deily (1996) estenderam a análise incluindo sanções não monetárias para as taxas de cumprimento da legislação de poluição do ar na indústria 
de aço dos Estados Unidos. Nadeau (1997) conclui que as atividades de monitoramento e aplicação da legislação reduzem o tempo em que as firmas estão em desacordo com os parâmetros de poluição do ar na indústria de papel americana.

Apesar de a maior parte dos artigos citados destacarem a importância das diversas formas de regulação formal e/ou informal para o cumprimento das normas ambientais, alguns trabalhos apontam para a ineficácia das sanções. Em artigo recente, Shimshack \& Ward (2010) demonstram empiricamente que direcionar recursos para o monitoramento e punição de firmas reincidentes é ineficiente, já que os ofensores frequentes têm custos de observância maiores e, portanto, têm menor probabilidade de responder a medidas de fiscalização e punição. Rousseau (2008), ao testar os efeitos da probabilidade de inspeção e do tamanho das multas aplicadas à indústria têxtil, não encontra evidências para a efetividade desta última. Dasgupta, Hettige e Wheeler (2000) estudam o impacto das características da firma, mercados, regulação formal e informal (pressão da comunidade) sobre o controle da poluição para fábricas mexicanas. Os autores encontram pouca evidência para a efetividade dos incentivos de mercado e nenhuma evidência quanto à regulação formal para a diminuição de emissões no setor industrial mexicano. Helland (1998) analisa a indústria de papel americana com respeito à regulação de poluição da água e conclui, em contraste com artigos anteriores, que as inspeções não afetam as taxas de cumprimento/ adequação à legislação. Sigman (1998) e Viladrich-Grau \& Groves (1997), estudando a indústria do petróleo, concluem que as multas não têm efeitos impeditivos sobre as infrações.

Em relação às evidências empíricas para o caso do Brasil, dois trabalhos se destacam. Ferraz e Seroa da Motta (2002) estudaram os impactos da regulação formal e informal sobre a decisão de investimento ambiental em indústrias do estado de São Paulo. O segundo, publicado por Seroa da Motta (2006), analisa os determinantes do desempenho ambiental de empresas brasileiras em relação às características da firma, às demandas das comunidades e aos incentivos de mercado.

O primeiro utiliza dados da pesquisa da atividade econômica de São Paulo (PAEP) em conjunto com dados municipais de regulação, economia política e condições socioeconômicas, para explicar a proba- 
bilidade de as unidades locais da indústria realizarem investimentos ambientais no ano de 1996.

Dada a característica dicotômica da variável investimento ambiental, é estimado um modelo probit para explicar os determinantes dessa variável. A variável dependente é definida como valor um se a empresa realizou algum tipo de investimento em substituição de insumos contaminantes, na reutilização e tratamento de resíduos ou no processo de produção da firma visando reduzir emissões. Entre as variáveis explicativas estão características da firma - tamanho, origem do capital, proporção de exportações, idade, setor em que a empresa está inserida (verde ou marrom), multas e advertências recebidas; e características da comunidade - número de postos da CETESB, número de ONGs ambientais, proporção de votos para candidatos do partido verde, níveis de escolaridade e renda, entre outras.

Os autores concluem que plantas com um maior número de trabalhadores têm uma maior probabilidade de fazer investimento ambiental, assim como empresas mais antigas e empresas com capital estrangeiro. Comprovando a tese de que firmas que exportam se beneficiam com algum tipo de diferenciação do produto "verde", plantas com maior proporção de exportação sobre vendas têm uma maior probabilidade de fazer investimento ambiental. Igualmente, os setores considerados mais poluentes têm uma maior probabilidade de realizar investimentos ambientais. O número de advertências recebidas pela firma é significativo no modelo enquanto que os fatores associados com regulação informal (votos, número de ONGs e renda) não se mostram significativos para explicar a decisão de investimento da firma (Ferraz e Seroa da Motta, 2002). Os autores argumentam que esses fatores explicaram de forma significativa a quantidade de advertências recebidas pela firma, sugerindo que para o caso brasileiro a organização local e pressão da comunidade têm impacto indireto sobre a firma, através de reclamações aos órgãos reguladores. Outra explicação para o fato da regulação informal não ter efeitos diretos sobre a decisão de investimento da firma está na eficiência da agência regulatória no estado de São Paulo.

Seroa da Motta (2006) complementa o artigo anterior analisando o papel de incentivos de mercado adicionais, tais como as reduções de custos geradas pelo controle ambiental e instrumentos de crédito go- 
vernamentais relacionados ao cumprimento das normas ambientais. Como proxy para o nível de controle ambiental o autor utiliza um indicador das práticas ambientais adotadas pela firma, que engloba o número de ações tomadas e a frequência das mesmas entre todas as firmas. Como variáveis explicativas, além das comuns ao estudo anterior, são utilizadas: acesso a crédito subsidiado, presença de ISO 14000 e variáveis dummy para a motivação em adotar práticas ambientais, relacionadas à diminuição dos custos de produção, aumento de competitividade nas exportações e melhoramentos na qualidade dos produtos. Os dados provêm da Pesquisa de Gestão Ambiental no Brasil para o ano de 1997, publicados pela CNI (1998), para 325 grandes e médias empresas. Os resultados encontrados confirmam a análise em Ferraz e Seroa da Motta (2002) e mostram que os incentivos de mercado adicionais têm um papel crucial sobre a decisão da firma quanto ao nível de controle ambiental. Apesar de a sabedoria convencional afirmar que as políticas de regulação são fracas no Brasil, Seroa da Motta (2006) demonstra que a gestão ambiental das empresas é altamente afetada pelo nível das sanções e que existe clara motivação para evitar tais punições. Assim, o resultado mais consistente do trabalho é que as demandas dos reguladores se constituem no principal determinante da adoção de práticas ambientais. Além disso, os requerimentos ambientais feitos pelo governo para concessão de crédito subsidiado têm criado incentivos para a melhoria do controle ambiental das empresas (Seroa da Motta, 2006).

\section{Referencial Teórico}

A visão tradicional de direito e economia, originada em Becker (1968), Stigler (1970) e Posner (1997), assume que a atitude criminosa decorre de uma análise racional dos custos e dos benefícios envolvidos com o crime, comparados com o retorno em dedicar tempo e recursos em atividades legais. ${ }^{2}$ Russell, Harrington \& Vaughan (1986) aplicaram esta estrutura ao controle da poluição, de modo que uma firma é interpretada como um agente econômico racional que decide violar os padrões ambientais quando a utilidade esperada da violação excede as punições esperadas (ou custos esperados) pela firma. Então, por exemplo, uma firma, ao decidir se despeja em um rio dejetos proibidos por lei, pondera os ganhos da infração (não

2 Para mais detalhes desta literatura ver Polinsky \& Shavell (2000).

Estud. Econ., São Paulo, vol. 44, n.1, p. 69-103, jan.-mar. 2014 
arcar com o custo de reciclagem ou de disposição correta), com a probabilidade de ser descoberta, o valor da multa e as demais sanções que sofrerá.

Além disso, a firma pode incorrer em custos indiretos se descoberta, tais como má publicidade ou relações desgastadas com o regulador (autoridade ambiental).

Assim, cometer um crime (ou uma infração) é uma variável de escolha que é influenciada pelos benefícios, que são conhecidos pela firma e pelos custos esperados, que são parcialmente incertos, uma vez que tanto a probabilidade quanto a magnitude de uma sanção são desconhecidos pela firma. Entretanto, as firmas podem reduzir esta incerteza observando o comportamento e as ações do regulador, ajustando suas expectativas quanto à possibilidade de serem descobertas e punidas (Shimshack \& Ward, 2005). A história do regulador em aplicar e garantir a lei é a principal fonte de informação para as firmas. Então, a firma observa a história do regulador em aplicar sanções sobre ela e sobre suas vizinhas. Quando a firma percebe que a autoridade ambiental faz cumprir a lei, isto é, aplica multas e demais sanções sobre ela e em firmas da mesma região ou localidade, ela ajusta para cima suas expectativas quanto à probabilidade dela ser descoberta e punida (Shimshack \& Ward, 2005; Sah, 1991).

Além da regulação formal, os agentes privados também podem atuar sobre a probabilidade de condenação, através do monitoramento, e sobre as sanções aplicadas, através das perdas de reputação e má publicidade, como exposto acima (Cohen, 2000; Almer \& Goeschl, 2010). Afsah et al. (1996), por exemplo, discutem um modelo com múltiplos agentes, em que o papel do governo como autoridade ambiental é complementado pela comunidade e pelo mercado como monitoradores. Assim, a decisão da firma em violar os padrões ambientais pode ser influenciada também por seus consumidores, pelos habitantes vizinhos a firma, por ONGs ambientais e demais grupos sociais defensores do meio ambiente. 


\subsection{O Modelo de Becker ${ }^{3}$}

Considere uma função que relaciona o número de ofensas de um agente à probabilidade de detenção, à punição se condenado, e outras variáveis, tais como renda disponível em atividades legais ou ilegais, o desejo de cometer infrações, etc. A relação pode ser representada por:

$$
O_{j}=O_{j}\left(p_{j}, f_{j}, u_{j}\right)
$$

onde $O_{j}$ é o número de ofensas que o indivíduo $j$ pode cometer durante um determinado período, $p_{j}$ é a probabilidade de condenação por ofensa, $f_{j}$ é a punição por ofensa, e $u_{j}$ contém todas as demais variáveis que influenciam a decisão do criminoso. Cabe lembrar que as distribuições de $p_{j}$ e $f_{j}$ dependem do juiz, júri, promotor, etc., em que o indivíduo $j$ se depara. Já a distribuição de $u_{j}$ depende das probabilidades de condenação e das punições de atividades ilegais concorrentes. Assim, há possibilidade de substituição entre os tipos de ofensas.

Como somente os ofensores condenados são de fato punidos, existe "discriminação de preço" e incerteza: se condenado, paga $f_{j}$ pela ofensa, com $f_{j}>0$, caso contrário, não paga pelo crime $\left(f_{j}=0\right)$. Um aumento em $p j$ ou $f_{j}$ reduz a utilidade esperada de uma ofensa e, portanto, tende a reduzir o numero de ofensas devido à probabilidade de "pagar" um maior "preço", ou o "preço" por si mesmo aumentaria. Ou seja:

e,

$$
O_{p_{j}}=\frac{\partial O_{j}}{\partial p_{j}}<0
$$

$$
O_{f_{j}}=\frac{\partial O_{j}}{\partial f_{j}}<0
$$

Com relação aos efeitos de $u_{j}$, temos, por exemplo, que um aumento na renda de atividades legais aumentaria o custo de oportunidade da infração, implicando um número de ofensas menor.

\footnotetext{
${ }^{3}$ Reproduzimos aqui parte do texto de Becker (1968).
} 
Uma mudança na forma da punição, por exemplo, de uma multa para encarceramento, também tenderia a reduzir o número de infrações.

Esse arcabouço teórico apresenta uma interpretação interessante quanto ao pressuposto de que um aumento na probabilidade de condenação tem efeito maior do que uma elevação na intensidade da punição sobre o número de ofensas. Conforme Becker (1968, pg. $178)^{4}$ "a convencional generalização de que os ofensores são mais desencorajados pela probabilidade de condenação do que pela punição quando condenado implica que os ofensores têm preferências pelo risco, pelo menos na região de punição relevante".

A utilidade esperada por cometer uma ofensa pode ser definida como:

$$
E U_{j}=p_{j} U_{j}\left(Y_{j}-f_{j}\right)+\left(1-p_{j}\right) U_{j}\left(Y_{j}\right)
$$

onde $Y_{j}$ é a renda monetária ou ganho monetário psicológico (monetary plus psychic) provenientes da ofensa, $U_{j}$ é a função utilidade, $p_{j}$ é a probabilidade de condenação, e $f_{j}$ é o valor monetário da punição. Então, pressupondo utilidade marginal positiva com a renda:

e,

$$
\frac{\partial E U_{j}}{\partial p_{j}}=U_{j}\left(Y_{j}-f_{j}\right)-U_{j}\left(Y_{j}\right)<0
$$

$$
\frac{\partial E U_{j}}{\partial f_{j}}=-p_{j} U_{j}^{\prime}\left(Y_{j}-f_{j}\right)<0
$$

Ou seja, um aumento em $p_{j}$ "compensado" por igual redução percentual em $f_{j}$ não modificaria a renda esperada da ofensa, $E Y_{j}=p_{j}\left(Y_{j}-f_{j}\right)+\left(1-p_{j}\right) Y_{j}=Y_{j}-p_{j} f_{j}$. Entretanto, a utilidade esperada poderia se modificar devido à alteração do risco. Assim, uma elevação de $p_{j}$ representaria uma redução no número de ofensas devido à redução da utilidade esperada advinda da execução do ato criminoso. Essa redução seria mais do que proporcional a uma equivalente elevação percentual em $f_{j}$ se o indivíduo for propenso ao risco.

4 Tradução livre. 
O incremento em $f_{j}$ teria um maior efeito sobre o número de ofensas se o indivíduo tivesse aversão ao risco; e teria o mesmo efeito se o indivíduo fosse neutro ao risco.

A oferta total de ofensas $(O)$ é a soma de todas as ofertas individuais $\left(O_{j}\right)$ e depende do conjunto de $p_{j}, u_{j}$ e $f_{j}$. Apesar de essas variáveis diferirem bastante entre os agentes, para simplificar, consideramos os valores médios, $p, f$ e $u$. Então, a função de mercado de ofensas (crimes) pode ser escrita como:

$$
O=O(p, f, u)
$$

Neste trabalho queremos testar o papel do regulador sobre a oferta de infrações contra o meio ambiente através do aumento da probabilidade de condenação $(p)$ e do valor da punição $(f)$. A ideia é que a autoridade ambiental (no caso, o IBAMA), ao aplicar multas, gera um efeito impeditivo tanto sobre a firma multada quanto sobre as firmas vizinhas (afetando $p$ ). Isto é, a reputação do regulador tem um efeito específico para a firma multada e um efeito spillover sobre as vizinhas. Quanto mais multas ou quanto maior a magnitude destas (alterando $f$ ), tanto maior será o efeito impeditivo não só sobre a firma multada, mas também sobre as firmas ao redor que observam o comportamento do regulador. Como não possuímos dados em nível das plantas (firmas), utilizamos dados agregados a nível estadual, onde a reputação do regulador tem um efeito sobre o estado (efeito específico) e um efeito spillover sobre os estados vizinhos. Vimos também que agentes privados, tais como as ONGs, ajudam a monitorar e a delatar firmas (aumentando $p$ ) e que as firmas podem sofrer custos indiretos se forem descobertas, na forma de má reputação, estigma moral, entre outros (afetando $f$ ). Além disso, dependendo das preferências da população quanto ao meio ambiente, os governos podem ser pressionados por suas populações a aumentarem tanto o nível de monitoramento quando as sanções aplicadas sobre infratores. Assim, incluímos na análise variáveis que captam o papel dos agentes privados no monitoramento (ONGs ambientais) e nas sanções informais (consciência ambiental da população). 


\section{Dados}

A fonte de dados primária deste artigo compreende a quantidade de autos de infração registrados pelo IBAMA e os valores das respectivas multas aplicadas para os anos de 2000 a 2011 em nível estadual. $\mathrm{Na}$ base, estão registrados autos de diversos tipos (categorias), incluindo infrações contra a flora, fauna, ecossistema, controle ambiental, cadastro técnico federal, entre outros. Os dados foram obtidos junto ao Ministério do Meio Ambiente (MMA) através do Sistema Eletrônico do Serviço de Informação ao Cidadão (e-SIC). Destacamos que esta base de dados, específica de infrações ambientais para os estados brasileiros, jamais foi utilizada para pesquisas no campo da economia ambiental e da economia do crime. Assim, as análises empregadas com estes dados constituem-se em uma novidade para o estudo das violações ambientais no Brasil e podem enriquecer o debate quando a aplicação de políticas públicas.

Neste trabalho empregamos como variável dependente o número de autos de infração contra a flora. A escolha desta variável, em detrimento das demais formas de infrações ambientais, ocorreu pela representatividade deste tipo de infração, tanto histórica, uma vez que a média de crimes contra a flora nos estados brasileiros é muito maior do que a média para as demais categorias (468 autos para a flora contra 199 autos para a fauna, a segunda principal categoria), quanto social (as discussões quando ao código florestal e a proteção da Mata Atlântica, Cerrado e Amazônia demonstram a preocupação da sociedade brasileira em relação a sua flora).

Os decretos 3.179/1998 e 6.514/2008 definem as seguintes infrações contra a flora: ${ }^{6}$ Destruir ou danificar floresta ou demais formas de vegetação natural em área considerada de preservação permanente, sem autorização do órgão competente; Cortar árvores em área considerada de preservação permanente ou cuja espécie seja especialmente protegida, sem permissão da autoridade competente; Causar dano direto ou indireto às unidades de conservação; Provocar incêndio em mata ou floresta; Fabricar, vender, transportar ou soltar balões; Cortar ou transformar em carvão madeira de lei; Receber ou adquirir, para fins comerciais ou industriais, madeira, lenha, carvão e outros produtos de origem vegetal, sem exigir a exibição de

5 O Decreto 6.514 substituiu o Decreto 3.179 tornando a legislação mais rígida e abrangente.

6 Para uma lista completa e atual das Infrações contra flora e das multas aplicáveis a cada caso, ver o Decreto 6.514 (Capítulo 1, Seção III, Subseção II). 
licença do vendedor; Impedir ou dificultar a regeneração natural de florestas ou demais formas de vegetação nativa em unidades de conservação; Executar manejo florestal sem autorização prévia do órgão ambiental competente, sem observar os requisitos técnicos estabelecidos; Desmatar, a corte raso, florestas ou demais formações nativas, fora da reserva legal, sem autorização da autoridade competente; Comercializar motosserra sem a respectiva licença, entre outros. Infelizmente, na base fornecida pelo MMA/IBAMA, os autos de infração estão registrados em "grandes categorias" (flora, fauna, cadastro técnico federal, licenciamento ambiental, etc.), de modo que não é possível determinar a origem de cada violação.

A Tabela 1 e a Figura 1 trazem uma visão geral dos autos de infração registrados para a flora durante os anos de 2000 a 2011, por estados e grandes regiões. É possível ver, por exemplo, que a região Norte possui a maior incidência média de infrações e que esta foi a única região a registrar uma variação positiva de violações entre o início e final do período analisado. Esta é também, historicamente, a região com a maior participação no total de violações registradas. No geral, houve queda no número de infrações para praticamente todos os estados brasileiros, com exceção dos estados da região Norte $(+12,4 \%)$, Mato Grosso $(+8,1 \%)$ e Distrito Federal $(+6,7 \%)$. Ocorreram em média 12.645 registros de infrações contra a flora no Brasil durante o período considerado. 
Tabela 1 - Infrações contra a flora (2000 - 2011)

\begin{tabular}{lccccc}
\hline Estado / Região & Ano 2000 & Ano 2005 & Ano 2011 & Média & Variação (\%) \\
& & & & $2000-2011$ & 2000 - 2011 \\
\hline AC & 136 & 321 & 157 & 297 & 15,4 \\
AM & 225 & 549 & 339 & 405 & 50,7 \\
AP & 91 & 228 & 83 & 108 & $-8,8$ \\
PA & 1.361 & 2.428 & 1.387 & 1.690 & 1,9 \\
RO & 951 & 1.577 & 1.073 & 1.269 & 12,8 \\
RR & 142 & 248 & 248 & 196 & 74,6 \\
TO & 215 & 311 & 221 & 294 & 2,8 \\
Norte & 3.121 & 5.662 & 3.508 & 4.259 & 12,4 \\
AL & 83 & 224 & 22 & 112 & $-73,5$ \\
BA & 803 & 743 & 364 & 637 & $-54,7$ \\
CE & 686 & 472 & 207 & 382 & $-69,8$ \\
MA & 411 & 639 & 197 & 460 & $-52,1$ \\
PB & 350 & 33 & 169 & 183 & $-51,7$ \\
PE & 406 & 273 & 92 & 230 & $-77,3$ \\
PI & 104 & 286 & 79 & 181 & $-24,0$ \\
RN & 227 & 193 & 95 & 213 & $-58,1$ \\
SE & 158 & 78 & 27 & 104 & $-82,9$ \\
Nordeste & 3.228 & 2.941 & 1.252 & 2.501 & $-61,2$ \\
DF & 30 & 71 & 32 & 41 & 6,7 \\
GO & 1.136 & 1.059 & 230 & 767 & $-79,8$ \\
MS & 277 & 709 & 83 & 458 & $-70,0$ \\
MT & 1.155 & 1.853 & 1.248 & 1.447 & 8,1 \\
Centro 0este & 2.598 & 3.692 & 1.593 & 2.713 & $-38,7$ \\
ES & 691 & 173 & 75 & 333 & $-89,1$ \\
MG & 1.798 & 628 & 277 & 1.329 & $-84,6$ \\
RJ & 172 & 166 & 5 & 120 & $-97,1$ \\
SP & 102 & 626 & 75 & 265 & $-26,5$ \\
Sudeste & 2.763 & 1.593 & 432 & 2.046 & $-84,4$ \\
PR & 201 & 367 & 162 & 284 & $-19,4$ \\
RS & 335 & 145 & 105 & 189 & $-68,7$ \\
SC & 527 & 2.195 & 92 & 653 & $-82,5$ \\
Sul & 1.063 & 2.707 & 359 & 1.126 & $-66,2$ \\
BRASIL & 12.773 & 16.595 & 7.144 & 12.645 & $-44,1$ \\
\hline
\end{tabular}

Fonte: Elaborada pelos autores utilizando dados disponibilizados pelo MMA/IBAMA.

Ao analisar os dados da Tabela 1 é possível perceber que, em geral, os estados com as maiores (menores) médias de infrações contra a flora também são os maiores (menores) estados em extensão de terra $\left(\mathrm{Km}^{2}\right)^{7}$. Neste trabalho a variável dependente, número de autos de infração contra a flora, é utilizada em valor absoluto.

7 É o caso dos estados do PA, MT e MG (entre os maiores) e AL, SE e DF (entre os menores). 
O leitor pode achar que seria recomendável a utilização da variável por seu equivalente em $\mathrm{Km}^{2}$. Entretanto, ocorre que o mais apropriado nesse caso é utilizar tais variáveis em termos absolutos, de forma a minimizar o efeito escala. Tal efeito seria ampliado com a variável com valores por $\mathrm{Km}^{2}$. Por exemplo, suponha que dois estados possuem o mesmo número de autos de infração por $\mathrm{Km}^{2}$, contudo, com autos de infração bastante distintos e, portanto, oferta de ofensas contra a flora também distintas.

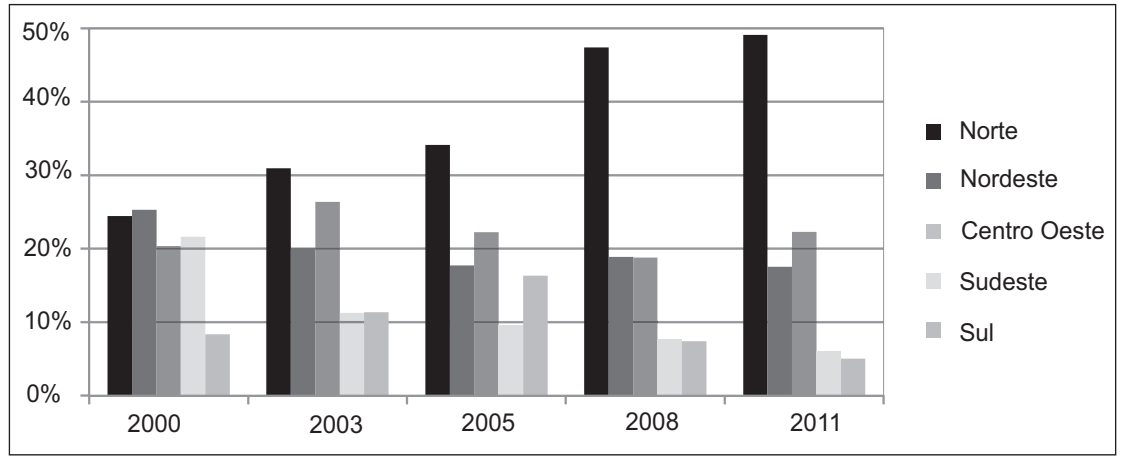

Figura 1 - Participação das regiões no total de infrações contra a flora Fonte: Elaborada pelos autores utilizando dados disponibilizados pelo MMA/IBAMA.

A principal variável explicativa empregada neste trabalho consiste no valor (magnitude) das multas lavradas pelo IBAMA. Esta variável também está presente na base disponibilizada pelo MMA. A Tabela 2 e a Figura 2 trazem uma visão geral das multas aplicadas para infrações contra a flora durante os anos de 2000 a 2011, por estados e grandes regiões. Novamente, na base fornecida, temos acesso somente aos valores agregados, de modo que não é possível determinar o valor específico de cada multa.

Assim como no caso das infrações registradas, a região Norte apresenta o maior valor médio das multas aplicadas (quase R\$185 mil por infração) e é, também, a região com a maior participação no total de multas aplicadas. Em quase todos os estados houve aumento significativo no valor da multa média aplicada, com exceção dos estados do Rio de Janeiro, Piauí e Paraná, onde este valor diminuiu. 
O estado do Amapá registrou a maior variação no período, onde a multa média em 2011 é 283,4 vezes maior do que o valor médio registrado para o ano 2000. Para o Brasil, vemos que a multa média aplicada no período cresceu 15,1 vezes, tendo como valor médio no período a cifra de $\mathrm{R} \$ 115.214,00$ por infração.

Por fim, a Figura 3 revela que, enquanto os autos de infração contra a flora apresentam uma tendência de queda no período estudado, os valores das multas aplicadas têm crescido ao longo do tempo no Brasil.

Tabela 2 - Valor médio (R\$) das multas aplicadas por infração (2000-2011)

\begin{tabular}{|c|c|c|c|c|c|}
\hline Estado / Região & Ano 2000 & Ano 2005 & Ano 2011 & $\begin{array}{c}\text { Média } \\
2000-2011\end{array}$ & $\begin{array}{c}\text { Variação } \\
2000 \text { - } 2011\end{array}$ \\
\hline$A C$ & 2.264 & 11.279 & 60.492 & 31.771 & 26,7 \\
\hline AM & 9.390 & 114.885 & 297.269 & 191.960 & 31,7 \\
\hline AP & 505 & 45.672 & 143.224 & 62.632 & 283,4 \\
\hline PA & 131.035 & 245.677 & 1.007 .092 & 325.726 & 7,7 \\
\hline RO & 20.927 & 83.648 & 187.009 & 83.084 & 8,9 \\
\hline $\mathrm{RR}$ & 1.380 & 41.033 & 73.527 & 112.304 & 53,3 \\
\hline TO & 7.213 & 58.322 & 119.511 & 50.407 & 16,6 \\
\hline Norte & 64.868 & 147.269 & 502.937 & 184.704 & 7,8 \\
\hline $\mathrm{AL}$ & 6.004 & 5.197 & 51.557 & 13.106 & 8,6 \\
\hline BA & 4.787 & 36.532 & 136.529 & 49.953 & 28,5 \\
\hline CE & 2.520 & 73.952 & 15.548 & 15.806 & 6,2 \\
\hline MA & 10.427 & 387.877 & 89.821 & 109.376 & 8,6 \\
\hline PB & 2.332 & 4.583 & 10.917 & 12.170 & 4,7 \\
\hline PE & 7.753 & 3.729 & 76.712 & 11.886 & 9,9 \\
\hline $\mathrm{Pl}$ & 52.214 & 18.396 & 17.659 & 26.311 & 0,3 \\
\hline $\mathrm{RN}$ & 1.472 & 3.886 & 24.363 & 6.470 & 16,6 \\
\hline SE & 1.806 & 4.583 & 29.533 & 5.708 & 16,4 \\
\hline Nordeste & 6.311 & 108.332 & 68.014 & 40.516 & 10,8 \\
\hline DF & 2.022 & 11.424 & 66.204 & 50.142 & 32,7 \\
\hline GO & 5.599 & 19.202 & 259.303 & 17.425 & 46,3 \\
\hline MS & 15.089 & 33.340 & 201.712 & 104.570 & 13,4 \\
\hline MT & 44.222 & 152.527 & 541.814 & 276.458 & 12,3 \\
\hline Centro Oeste & 23.741 & 88.683 & 473.750 & 170.821 & 20,0 \\
\hline ES & 2.275 & 5.524 & 16.385 & 7.861 & 7,2 \\
\hline$M G$ & 2.105 & 21.828 & 282.587 & 36.795 & 134,2 \\
\hline RJ & 20.384 & 35.815 & 6.200 & 17.510 & 0,3 \\
\hline SP & 13.852 & 60.319 & 16.013 & 30.940 & 1,2 \\
\hline Sudeste & 3.719 & 36.641 & 186.892 & 30.210 & 50,3 \\
\hline PR & 106.642 & 188.534 & 100.171 & 112.825 & 0,9 \\
\hline RS & 3.394 & 9.221 & 24.419 & 11.681 & 7,2 \\
\hline SC & 4.486 & 11.004 & 21.537 & 14.472 & 4,8 \\
\hline Sul & 23.458 & 34.977 & 57.864 & 38.768 & 2,5 \\
\hline BRASIL & 25.030 & 98.398 & 378.730 & 115.214 & 15,1 \\
\hline
\end{tabular}

Fonte: Elaborada pelos autores utilizando dados disponibilizados pelo MMA/IBAMA. 
A magnitude das multas é uma variável importante para a decisão de observância da lei ambiental, já que o valor monetário de uma sanção entra diretamente na função de custo esperado de uma violação ambiental. Seguindo o procedimento adotado por outros autores (tais como Shimshack \& Ward, 2005, 2008), utilizamos o valor defasado das multas em 1 (um) e 2 (dois) anos para cada estado. Nossa estratégia empírica é, portanto, ligar as multas ao comportamento subsequente de observância da lei ambiental por parte dos agentes econômicos. Em conformidade com nosso modelo teórico, dividimos os efeitos de uma multa em duas partes: um efeito específico para cada estado, englobando multas defasadas em um e dois períodos (Multas); e um efeito spillover dos estados vizinhos (Multas Vizinhos). Este, por sua vez, é testado de duas formas: vizinhos fronteiriços e vizinhos regionais. O efeito spillover dos estados fronteiriços corresponde à média das multas lavradas nos estados fronteiriços ao estado analisado, defasadas em um ano (Multas Vizinhos F); já o efeito spillover dos estados regionais ${ }^{8}$ corresponde à média das multas lavradas nos estados pertencentes à região do estado analisado, defasadas em um ano (Multas Vizinhos R).

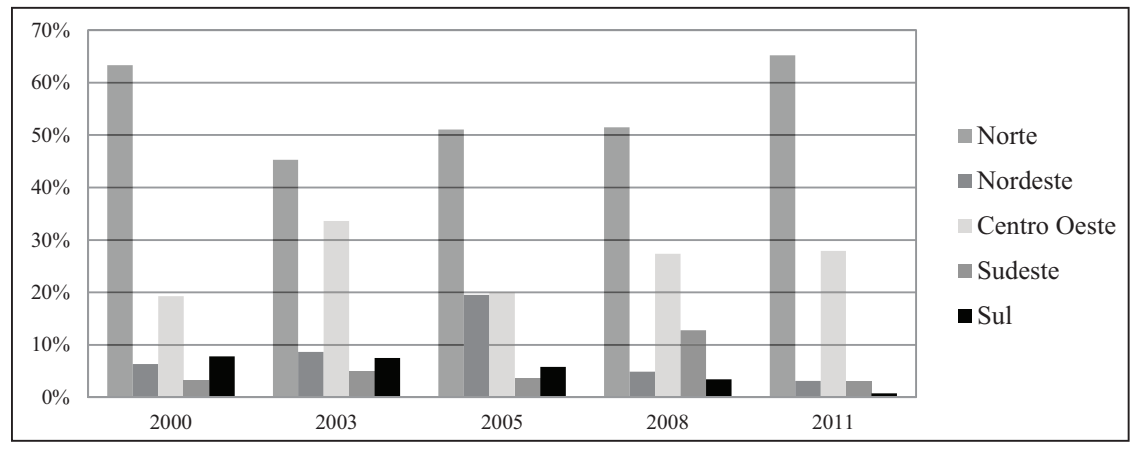

Figura 2 - Participação das regiões no total de multas aplicadas

Fonte: Elaborada pelos autores utilizando dados disponibilizados pelo MMA/IBAMA.

8 Uma justificativa para o uso desta variável é que os agentes econômicos podem obter facilmente informações quanto à atuação do IBAMA em outros estados do Brasil que não somente nos estados fronteiriços. Entretanto, as características geográficas/culturais/socioeconômicas tendem a ser mais parecidas dentro dos estados de uma região do que entre regiões. Outro ponto relevante é a amplitude do Brasil em relação à capacidade de fiscalização do IBAMA, isto é, o aumento das autuações em certas regiões pode não ser percebido pelo infrator como aumento da fiscalização no seu estado, se as regiões forem muito distantes uma da outra. 


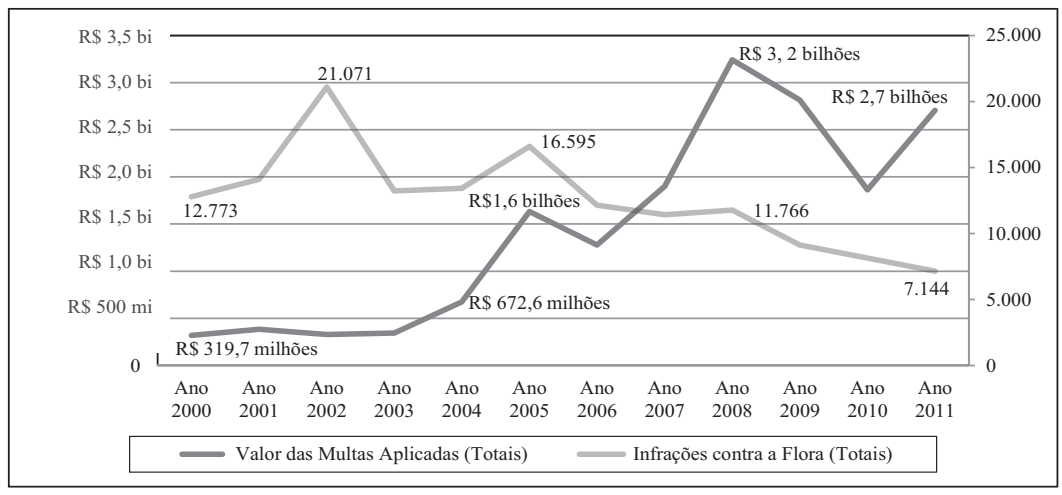

Figura 3 - Evolução das infrações contra a flora e multas aplicadas no Brasil Fonte: Elaborada pelos autores utilizando dados disponibilizados pelo MMA/IBAMA.

Para complementar a análise da regulação formal (o papel da autoridade ambiental) no combate às infrações ambientais, empregamos também o gasto com controle ambiental feito por cada estado (Gasto Controle). Essa variável está discriminada na Execução Orçamentária dos Estados ${ }^{9}$ e refere-se ao gasto que cada estado dirige para o combate e prevenção de infrações ambientais (dentro da função Gestão Ambiental). Essa variável de gasto é sugerida por Stafford (2002, 2003) como parte do esforço do governo em monitorar infrações ambientais, uma vez que ela atua diretamente sobre a probabilidade de detecção de um crime contra o meio ambiente. Como o gasto com controle ambiental pode estar diretamente relacionado ao número de autos de infração, empregamos os valores de gasto estadual defasados em 1 (um) período. O uso desta variável defasada é coerente com os demais estudos recentes na área de crime ambiental.

Aqui cabe uma pequena nota quanto ao problema da causalidade reversa. Segundo Gray \& Shimshack (2011), para tratar as complicações associadas à causalidade reversa os estudos recentes examinam as relações entre o desempenho ambiental atual das firmas e valores defasados de monitoramento e de aplicação da legislação, em vez de relações entre o desempenho ambiental atual e os valores atuais das sanções. Enquanto é provável que o descumprimento atual da legislação induza as ações tomadas pelo regulador hoje e no futuro próximo (esforço despendido para descobrir e coibir infrações), não

9 Disponível no site do Ministério da Fazenda / Secretaria do Tesouro Nacional, para os anos de 2004 a 2011. 
parece plausível supor que as infrações atuais afetam as ações tomadas pela autoridade ambiental no passado. Além de resolver este problema, o uso de variáveis defasadas é adequado para representar a história do regulador em descobrir infrações e aplicar sanções que se constitui na principal fonte de informações para a formulação de expectativas das firmas. Nosso pressuposto básico é que as firmas aprendem sobre a probabilidade e a magnitude das sanções observando o comportamento recente do regulador tanto sobre elas, como sobre outras firmas.

Outro problema importante que pode surgir na análise é o viés de variável omitida. Este problema ocorre quando fatores não incluídos no modelo influenciam simultaneamente o número de violações e a atividade da autoridade ambiental. Por exemplo, comunidades sensíveis às questóes ambientais podem pressionar o regulador a aumentar o monitoramento e a elevar o nível das sanções e podem, ao mesmo tempo, exigir que as empresas adotem processos de produção mais limpos (Gray \& Shimshack, 2011).

Para minimizar esse problema, diversos estudos incluem variáveis socioeconômicas para representar o papel das comunidades (por exemplo, Almer \& Goeschl, 2010; Anton et al., 2004 e Earnhart, 2004). Em nossa análise nós incluímos o Produto Interno Bruto per capita de cada estado (PIB $p c)$ e seu termo quadrado $\left(P I B p c^{2}\right),{ }^{10}$ a presença de ONGs ambientais atuando no estado e em estados vizinhos ${ }^{11}$ (ONGs), uma variável para consciência ambiental da população (dada pelo percentual de votos no partido verde nas três últimas eleições para deputado federal ${ }^{12}$ para cada estado), a taxa de urbanização de cada estado ${ }^{13}$ (percentual da população vivendo em áreas urbanas) e uma dummy para mudança na legislação brasileira quanto às infrações e sanções relativas ao meio ambiente (Legislação), ocorrida no ano de 2008.

Quanto ao uso das variáveis $P I B p c$ e $P I B p c^{2}$ estas cumprem duas funções. Em primeiro lugar, aumentos de renda refletem aumentos na produção, indicando que pode haver maior incidência de polui-

10 Disponível no Instituto Brasileiro de Geografia e Estatística (IBGE), até 2009.

${ }^{11}$ Disponível no Cadastro Nacional de Entidades Ambientalistas do Conselho Nacional do Meio Ambiente (CONAMA /MMA), para todo o período analisado.

12 Disponível no Tribunal Superior Eleitoral (TSE) para as eleições de 1998, 2002 e 2006.

${ }^{13}$ Calculado a partir de dados da Pesquisa Nacional de Amostra por Domicílio (PNAD/IBGE) quanto à população residente rural e urbana, disponível para anos de 2001 a 2009. 
ção, degradação e desmatamento. Entretanto, conforme a sociedade enriquece ocorre substituição da produção, de indústrias sujas para limpas, assim como avanços tecnológicos redutores da degradação ambiental, o que pode reduzir a incidência de infrações ambientais. Esta hipótese é expressa pela literatura da Curva de Kuznets Ambiental (CKA), originada em Grossman \& Krueger (1995). Em segundo lugar, a variável PIB $p c$ pode ser utilizada como proxy para o retorno da atividade ilegal. A ideia é que um aumento na renda do crime implica maior probabilidade do agente engajar-se na atividade criminal (Ehrlich, 1973), que pode apresentar retornos decrescentes de escala. Além de tais funções, O PIB pc reflete outros fatores associados às comunidades, tais como o nível educacional, taxa de pobreza e indicadores de saúde.

A utilização da variável ONGs reflete o papel dos agentes privados no monitoramento das firmas. Além disso, as ONGs atuam como reveladoras de informação do comportamento das firmas para o restante da sociedade (perdas de reputação e má publicidade), isto é, as ONGs relatam violações dos padrões ambientais para a sociedade através da mídia (Uhr, Uhr \& Mueller, 2012). Na nossa análise usamos ONGs atuando no estado e em estados vizinhos já que o estabelecimento de parcerias e projetos é comum entre as entidades ambientalistas, isto é, as ONGs possuem uma característica de grupo na medida em que buscam fortalecer umas às outras (Uhr, Uhr \& Mueller, 2012) ${ }^{14}$.

Seguindo os trabalhos de Almer \& Goelsch (2010) e Seroa da Motta (2006), incluímos a variável Consciência Ambiental, que reflete a sensibilidade da população do estado quanto às questões ambientais e a preferência por um meio ambiente sustentável, além de ser uma proxy para a pressão que os consumidores exercem sobre as firmas (Anton et al., 2004). Tanto a variável de Consciência Ambiental quanto a variável ONGs procuram medir o papel dos agentes privados no combate e controle a infrações ambientais.

A variável Tx Urbanização caracteriza a concentração populacional do estado em centros urbanos, ou seja, é a razão entre população urbana e o total da população estadual. A taxa de urbanização serve como proxy para o papel das comunidades em monitorar e delatar

${ }^{14}$ Para mais informações sobre a atuação das ONGs ambientais no Brasil, ver a publicação Análise de Gestão Ambiental 2010/2011, disponível em http://www.analise.com/index. $\mathrm{php} /$ site/publicacoes/exibe/3/analise-gestao-ambiental. 
infrações ambientais, isto é, quanto maior a taxa de urbanização, maior é a facilidade em monitorar o comportamento das firmas e em informar as suas ações para a autoridade ambiental. Além disso, esperamos uma relação inversa entre a taxa de urbanização e a incidência de infrações contra a flora já que a própria definição desta variável (tipos de autos) está mais relacionada a características de áreas não urbanas.

Por fim, a dummy para a mudança na legislação reflete o aumento das penalidades para infrações cometidas contra o meio ambiente. No ano de 2008, o governo brasileiro lançou o Decreto 6.514 que dispõe sobre as infrações e sanções administrativas ao meio ambiente, substituindo o Decreto 3.179 que tratava do mesmo tema. A diferença entre os dois decretos, em relação a infrações contra a flora, encontra-se no aumento dos tipos de infração (de 17 tipos de infrações para 18) e das penalidades (principalmente nos valores mínimos das multas aplicadas), na inclusão de novos agravantes (por exemplo, se a infração ocorrer em região de Mata Atlântica ou se houver reincidência em um período de até cinco anos) e da exclusão do termo de ajustamento de conduta (que permitia ao infrator livrarse do pagamento da multa, uma vez assinado o termo). Esta variável segue a proposta de Stafford $(2002,2003)$.

A Tabela 3 resume as variáveis explicativas utilizadas e a Tabela 4 apresenta as estatísticas descritivas.

Tabela 3 - Variáveis explicativas

\begin{tabular}{|c|c|c|}
\hline Variáveis Explicativas & Descrição & Sinal Esperado \\
\hline Multas & Multas aplicadas no estado (magnitude) em t-1 e t-2 & Negativo \\
\hline Multas Vizinhos F & $\begin{array}{l}\text { Multas médias aplicadas em estados vizinhos fronteiriços } \\
\text { (magnitude) em t-1 }\end{array}$ & Negativo \\
\hline Multas Vizinhos R & $\begin{array}{l}\text { Multas médias aplicadas em estados da mesma região } \\
\text { geográfica (magnitude) em t-1 }\end{array}$ & Negativo \\
\hline Gasto Controle & Percentual do Gasto estadual com controle ambiental em t-1 & Negativo \\
\hline $\mathrm{PIB} p \mathrm{pc}$ & Renda per capita do estado & Positivo \\
\hline $\mathrm{PIB} p c^{2}$ & Renda per capita do estado ao quadrado & Negativo \\
\hline ONGs & $\begin{array}{l}\text { Número de ONGs ambientais atuando no estado e em } \\
\text { estados vizinhos }\end{array}$ & Negativo \\
\hline Consciência Ambiental & $\begin{array}{l}\text { Razão entre votos para deputados federais do partido verde } \\
\text { e total de votos válidos }\end{array}$ & Negativo \\
\hline Tx Urbanização & Percentual da população vivendo em áreas urbanas & Negativo \\
\hline Legislação & $\begin{array}{l}\text { Dummy para mudança na legislação (igual a } 1 \text { a partir de } \\
\text { 2008, igual a } 0 \text { caso contrário). }\end{array}$ & Negativo \\
\hline
\end{tabular}

Fonte: Elaborada pelos autores. 
Tabela 4 - Estatísticas descritivas

\begin{tabular}{lccccc}
\hline \multicolumn{1}{c}{ Variáveis } & Observações & Média & Desvio-padrão & Mín & Máx \\
\hline Autos de Infração & 324 & 468,32 & 703,91 & 5 & 9.899 \\
Multas & 324 & $\mathrm{R} \$ 32,5 \mathrm{mi}$ & $\mathrm{R} \$ 94,1 \mathrm{mi}$ & $\mathrm{R} \$ 15.333,69$ & $\mathrm{R} \$ 736 \mathrm{mi}$ \\
Multas Vizinhos F & 324 & $\mathrm{R} \$ 52,7 \mathrm{mi}$ & $\mathrm{R} \$ 94,6 \mathrm{mi}$ & $\mathrm{R} \$ 529.777,40$ & $\mathrm{R} \$ 736 \mathrm{mi}$ \\
Multas Vizinhos R & 324 & $\mathrm{R} \$ 133 \mathrm{mi}$ & $\mathrm{R} \$ 195 \mathrm{mi}$ & $\mathrm{R} \$ 777.198,94$ & $\mathrm{R} \$ 825 \mathrm{mi}$ \\
Gasto Controle & 216 & 0,00063 & 0,00009 & 0,0000 & 0,00687 \\
PIB pc & 270 & $\mathrm{R} \$ 6.156,71$ & $\mathrm{R} \$ 3.856,25$ & $\mathrm{R} \$ 1.615,81$ & $\mathrm{R} \$ 24.357,46$ \\
ONGs & 324 & 93,27 & 75,18 & 8 & 368 \\
Consciência Ambiental & 268 & 0,0088636 & 0,0126748 & 0,0000 & 0,05457 \\
Tx Urbanização & 225 & 79,7124 & 9,2052 & 60,71 & 98,21 \\
Legislação & 324 & 0,33333 & 0,47213 & 0 & 1 \\
\hline
\end{tabular}

Fonte: Elaborada pelos autores utilizando o software Stata.

Uma vez que grande parte das infrações contra a flora ocorre nas regiões Norte e Centro Oeste (como demonstrado anteriormente), e é caracterizada por situações de desmatamento ou exploração inadequada de áreas nativas, poderíamos incluir na análise econométrica variáveis explicativas apontadas pela literatura de desmatamento para a Amazônia brasileira. ${ }^{15}$ As causas do desmatamento investigadas pela literatura são amplas: geográficas (qualidade do solo, temperatura, chuvas), de acessibilidade (distância de mercados, rodovias) e socioeconômicas (renda, educação, produção agrícola, urbanização, etc.). O uso destas variáveis neste estudo fica dificultado por diversos motivos, dos quais cabe citar: em primeiro lugar, muitos dos determinantes do desmatamento são características peculiares de uma microrregião ou município (localização geofísica/espacial, ao passo que nossos dados são agregados por UFs) e, em segundo lugar, a maior parte destas variáveis não está disponível para as demais regiões brasileiras. Entretanto, muitas destas variáveis são invariantes no tempo, isto é, são características individuais que são controladas pelo método econométrico a ser aplicado. ${ }^{16}$

15 Para uma revisão ampla dos determinantes do desmatamento na Amazônia Legal e outras regiões, os autores indicam a leitura dos seguintes textos: Chomitz \& Gray (1996), Chomitz \& Thomas (2003), Margulis (2003), Nelson \& Geoghegan (2002), Oliveira et al. (2011), Pfaff (1999) e Pfaff et al. (2007).

${ }^{16}$ A metodologia de painel controla a existência de características geográficas/culturais/socioeconômicas dos estados que não foram especificadas no modelo, mas que são praticamente constantes no período estudado, tais como malha rodoviária, distância de mercados consumidores, médias de temperatura e pluviosidade e se estado é, historicamente, produtor agrícola. 


\section{Modelo Econométrico}

O modelo básico que desejamos estimar é:

$\gamma_{\mathrm{it}}=\alpha+\beta_{1} \mathrm{M}_{\mathrm{i}, \mathrm{t}-1}+\beta_{2} \mathrm{M}_{\mathrm{i}, \mathrm{t}-2}+\varphi \mathrm{V}_{\mathrm{i}, \mathrm{t}-1}+\mu \mathrm{G}_{\mathrm{i}, \mathrm{t}-1}+\mathrm{X}_{\mathrm{it}}^{\prime} \delta+c_{i}+\varepsilon_{\mathrm{it}}$

onde $i$ indexa a unidade de variação $(i=1, \ldots, 27)$, isto é, os estados brasileiros, e $t$ indexa a unidade de tempo $(t=2000, \ldots, 2011) ; \gamma_{\text {it }}$ é o logaritmo natural da oferta de infrações ambientais (autos de infração para a flora); $\alpha$ representa a constante; $M$ representa as multas aplicadas no estado, a variável $V$ representa as multas aplicadas nos estados vizinhos (fronteiriços ou regionais); $G$ representa os gastos estaduais com controle ambiental; vetor $\mathrm{X}_{\mathrm{it}}$ contém as demais variáveis explicativas discutidas anteriormente. $\mathrm{O}$ conjunto $\left(\beta_{1}, \beta_{2}, \varphi, \mu, \delta\right)$ são os parâmetros a serem estimados; o termo $c_{i}$ representa a heterogeneidade estadual, ou seja, contém as características específicas do estado $i$ que não mudam no tempo e, por fim, $\varepsilon_{i t}$ é o termo do erro. Todas as variáveis explicativas estão em logaritmo natural (com exceção da variável Legislação).

Dada a dimensão temporal e espacial da nossa amostra, a análise com técnicas de dados em painel é indicada. Como os dados em painel se relacionam a indivíduos, empresas, estados, etc., tende a haver muita heterogeneidade nessas unidades que não é observada explicitamente. Uma variável não observada e constante no tempo é chamada de efeito não observado ou heterogeneidade individual (o termo $c_{i}$ da equação de regressão). Esta variável captura características dos estados que não mudam no tempo como, por exemplo, características culturais da população ou características geográficas. A motivação primária para usar dados de painel é resolver o problema da heterogeneidade individual, que é tratada como uma variável aleatória e não um parâmetro a ser estimado.

É possível que $c_{i}$ esteja arbitrariamente correlacionada com as demais variáveis explanatórias no nosso modelo, uma vez que essas características não observadas podem afetar o esforço da autoridade ambiental para descobrir violações e aplicar multas, além de afetar as preferências da população quanto ao meio ambiente (influenciando a presença de ONGs ambientais e os votos no Partido Verde, por exemplo). 
Neste caso, o método de Efeitos Fixos (Fixed Effects - FE) permite estimar os efeitos parciais consistentemente. ${ }^{17} \mathrm{O}$ ponto central da metodologia de Efeitos Fixos é transformar as equações (no nosso caso utilizamos a transformação within) para eliminar a heterogeneidade individual. ${ }^{18}$

O objetivo principal da análise empírica é testar o papel do regulador sobre a oferta de infrações contra o meio ambiente (representado pelas variáveis Multas, Multas Vizinhos, Gasto Controle). As variáveis explicativas mais importantes são as multas aplicadas em cada estado, defasadas para um (1) e dois (2) anos, e as multas aplicadas sobre os estados vizinhos, defasadas em um (1) ano. Estas variáveis captam o efeito específico e o efeito spillover da reputação do regulador. Para complementar a análise empírica, testamos também se os agentes privados atuam na coibição das infrações ambientais (representado pelas variáveis ONGs e Consciência Ambiental).

\section{Resultados}

Nesta seção nós apresentamos e discutimos os resultados do nosso modelo econométrico. Uma das maneiras mais simples de estimar o modelo proposto na seção anterior é simplesmente empilhar as observações para cada estado e aplicar o método de Mínimos Quadrados Ordinários (POLS). Neste caso, o efeito individual de cada estado $\left(c_{i}\right)$ não é levado em consideração. O problema com este método é que, dada a presença da heterogeneidade estadual, confirmada pelo teste de Breusch-Pagan para efeitos aleatórios, os erros são serialmente correlacionados, tornando o método ineficiente. Além disso, como $c_{i}$ pode estar correlacionado às variáveis explicativas, os coeficientes estimados podem não ser consistentes. Assim, os resultados das estimações pelo método POLS não são apresentados devido à existência do componente não observado (heterogeneidade estadual) e sua possível correlação com as variáveis explicativas.

\footnotetext{
${ }^{17}$ Em comparação ao método de Efeitos Aleatórios (Random Effects - RE), que assume que não está correlacionado às variáveis explicativas.

${ }^{18}$ A transformação nas variáveis elimina toda e qualquer variável constante no tempo. Daí a impossibilidade de se incluir nas regressões características geográficas/culturais/socioeconômicas variantes entre estados, mas constantes no período de análise.
} 
De fato, o teste de Hausman mostra que o efeito não observado está correlacionado às variáveis explicativas em todas as estimações, confirmando que o método de Efeitos Fixos é o mais indicado para a estimação do nosso modelo. ${ }^{19}$

As Tabelas 5 e 6 apresentam os resultados do modelo considerando as variáveis Multas Vizinhos F e Multas Vizinhos $R$, respectivamente. As regressões são estimadas por Efeitos Fixos em quatro grupos distintos: o primeiro focando no papel do regulador (FE 1), o segundo inclui as variáveis de Produto Interno Bruto per capita como controles (FE 2), o terceiro apresenta o modelo que inclui a ação dos agentes privados (FE 3) e, por fim, o quarto inclui todas as variáveis, considerando os efeitos da mudança na legislação e da taxa de urbanização (FE 4).

Tabela 5 - Resultados para vizinhos fronteiriços utilizando o método de efeitos fixos

\begin{tabular}{|c|c|c|c|c|}
\hline Variáveis Independentes & FE 1 & FE 2 & FE 3 & FE 4 \\
\hline \multirow[b]{2}{*}{ Multas $_{t-1}$} & 0,04 & $-0,10^{*}$ & $-0,09$ & $-0,12^{\star \star}$ \\
\hline & $(0,07)$ & $(0,05)$ & $(0,05)$ & $(0,05)$ \\
\hline \multirow{2}{*}{ Multas $_{t-2}$} & $-0,06^{*}$ & $-0,11^{* *}$ & $-0,11^{* *}$ & $-0,16^{* * *}$ \\
\hline & $(0,03)$ & $(0,05)$ & $(0,05)$ & $(0,05)$ \\
\hline \multirow{2}{*}{ Multas Vizinhos $F_{t-1}$} & $-0,18^{\star \star \star}$ & $-0,19^{* * *}$ & $-0,17^{* * *}$ & $-0,16^{* \star *}$ \\
\hline & $(0,05)$ & $(0,04)$ & $(0,04)$ & $(0,03)$ \\
\hline \multirow{2}{*}{ Gasto Controle $_{t-1}$} & $-0,04$ & $-0,02$ & $-0,02$ & $-0,02$ \\
\hline & $(0,04)$ & $(0,02)$ & $(0,02)$ & $(0,02)$ \\
\hline \multirow{2}{*}{$P I B p c$} & & $44,18^{* *}$ & $40,64^{* *}$ & $38,67^{* \star}$ \\
\hline & & $(17,58)$ & $(16,06)$ & $(15,81)$ \\
\hline \multirow[t]{2}{*}{$P I B p c^{2}$} & - & $-2,61^{\star *}$ & $-2,37^{* *}$ & $-2,26^{* *}$ \\
\hline & & $(1,01)$ & $(0,916)$ & $(0,89)$ \\
\hline ONGs & - & - & $\begin{array}{l}-1,18 \\
(1,51)\end{array}$ & $\begin{array}{r}-0,80 \\
(1,64)\end{array}$ \\
\hline \multirow{2}{*}{ Consciência Ambiental } & - & - & $-0,08^{*}$ & $-0,09^{*}$ \\
\hline & & & $(0,05)$ & $(0,04)$ \\
\hline Tx Urbanização & - & - & - & $\begin{array}{l}9,82^{2^{*}} \\
(4,66)\end{array}$ \\
\hline \multirow{2}{*}{ Legislação } & & - & & $-0,18^{*}$ \\
\hline & & & & $(0,10)$ \\
\hline \multirow{2}{*}{ Constante } & $8,35^{\star \star *}$ & $-174,48^{* *}$ & $-157,34^{\star *}$ & $-192,08^{\star * \star}$ \\
\hline & $(1,92)$ & $(76,01)$ & $(70,48)$ & $(60,80)$ \\
\hline $\mathrm{R}^{2}$ & 0,10 & 0,40 & 0,41 & 0,45 \\
\hline Teste F & $7,17^{* \star *}$ & $10,85^{\star * *}$ & $8,19^{* * *}$ & $7,82^{\star * *}$ \\
\hline Teste Breusch Pagan & $21,17^{\star \star \star}$ & $4,46^{* *}$ & $5,05^{\star \star}$ & $7,59^{\star \star *}$ \\
\hline Teste de Hausman & $69,27^{\star * *}$ & $230,94^{\star \star \star}$ & $183,64^{\star \star *}$ & $131,04^{\star \star *}$ \\
\hline Observações & 172 & 123 & 121 & 121 \\
\hline
\end{tabular}

Os valores entre parênteses são os erros padrões das variáveis. Regressões robustas a heterocedasticidade. O nível de significância estatística é dado por: ${ }^{*}=10 \%,{ }^{* *}=5 \%$ e ${ }^{* * *}=1 \%$.

Fonte: Elaborada pelos autores utilizando o software Stata.

${ }^{19}$ Em comparação ao método POLS e RE (ver nota de rodapé anterior). 
Tabela 6 - Resultados para vizinhos regionais utilizando o método de efeitos fixos

\begin{tabular}{|c|c|c|c|c|}
\hline Variáveis Independentes & FE 1 & FE 2 & FE 3 & FE 4 \\
\hline Multas $_{t-1}$ & $\begin{array}{r}0,06 \\
(0,08)\end{array}$ & $\begin{array}{c}-0,08 \\
(0,06)\end{array}$ & $\begin{array}{c}-0,08 \\
(0,06)\end{array}$ & $\begin{array}{l}-0,10 \\
(0,06)\end{array}$ \\
\hline Multas $_{t-2}$ & $\begin{array}{c}-0,08^{* *} \\
(0,03)\end{array}$ & $\begin{array}{l}-0,13^{* *} \\
(0,05)\end{array}$ & $\begin{array}{l}-0,13^{* *} \\
(0,05)\end{array}$ & $\begin{array}{c}-0,18^{* * *} \\
(0,05)\end{array}$ \\
\hline Multas Vizinhos $\boldsymbol{R}_{t-1}$ & $\begin{array}{c}-0,17^{* * *} \\
(0,05)\end{array}$ & $\begin{array}{c}-0,17^{\star \star \star} \\
(0,04)\end{array}$ & $\begin{array}{c}-0,15^{\star * *} \\
(0,04)\end{array}$ & $\begin{array}{c}-0,14^{\star * *} \\
(0,05)\end{array}$ \\
\hline Gasto Controle $_{t-1}$ & $\begin{array}{l}-0,06 \\
(0,04)\end{array}$ & $\begin{array}{l}-0,06^{* *} \\
(0,02)\end{array}$ & $\begin{array}{l}-0,05^{* *} \\
(0,02)\end{array}$ & $\begin{array}{l}-0,05^{* *} \\
(0,02)\end{array}$ \\
\hline$P I B p c$ & - & $\begin{array}{l}46,63^{\star *} \\
(19,60)\end{array}$ & $\begin{array}{l}41,69^{\star *} \\
(18,14)\end{array}$ & $\begin{array}{l}41,59^{\star *} \\
(17,32)\end{array}$ \\
\hline$P I B p c^{2}$ & - & $\begin{array}{l}-2,76^{* *} \\
(1,13)\end{array}$ & $\begin{array}{l}-2,50^{*} \\
(0,92)\end{array}$ & $\begin{array}{l}-2,44^{* *} \\
(0,98)\end{array}$ \\
\hline ONGs & - & - & $\begin{array}{l}-1,20 \\
(1,87)\end{array}$ & $\begin{array}{l}-0,44 \\
(1,99)\end{array}$ \\
\hline Consciência Ambiental & - & - & $\begin{array}{l}-0,09^{*} \\
(0,05)\end{array}$ & $\begin{array}{l}-0,09^{*} \\
(0,05)\end{array}$ \\
\hline Tx Urbanização & - & - & - & $\begin{array}{c}10,06^{* *} \\
(4,87)\end{array}$ \\
\hline Legislação & - & - & - & $\begin{array}{l}-0,24^{\star} \\
(0,11)\end{array}$ \\
\hline Constante & $\begin{array}{c}8,18^{* \star *} \\
(1,66)\end{array}$ & $\begin{array}{c}-184,30^{* *} \\
(75,46)\end{array}$ & $\begin{array}{c}-165,52^{* *} \\
(79,44)\end{array}$ & $\begin{array}{c}-207,07^{\star * *} \\
(66,51)\end{array}$ \\
\hline $\mathrm{R}^{2}$ & 0,09 & 0,37 & 0,39 & 0,44 \\
\hline Teste F & $7,82^{* * *}$ & $5,58^{* * *}$ & $4,57^{* \star *}$ & $6,35^{* \star *}$ \\
\hline Teste Breusch Pagan & $28,58^{\star * *}$ & $6,67^{\star *}$ & $7,16^{\star *}$ & $9,33^{\star * \star}$ \\
\hline Teste de Hausman & $72,97^{* * *}$ & $129,11^{\star * *}$ & $151,24^{* * *}$ & $129,08^{* * *}$ \\
\hline Observações & 172 & 123 & 121 & 121 \\
\hline
\end{tabular}

Os valores entre parênteses são os erros padrões das variáveis. Regressões robustas a heterocedasticidade. O nível de significância estatística é dado por: ${ }^{*}=10 \%,{ }^{* *}=5 \% \mathrm{e}^{* * *}=1 \%$.

Fonte: Elaborada pelos autores utilizando o software Stata.

Controlando a heterogeneidade estadual através do método de Efeitos Fixos obtemos resultados empíricos condizentes com nosso modelo teórico e nossas hipóteses quanto às variáveis. Tanto nas regressões com vizinhos fronteiriços (Tabela 5) quanto nas regressões com vizinhos regionais (Tabela 6), os sinais dos coeficientes das variáveis Multas $_{t-1}$ e Multas ${ }_{t-2}$ são negativos (com exceção do sinal da variável Multas ${ }_{t-1}$, que é positivo em FE 1). Os coeficientes da variável Multas $_{t-2}$ são significativos em todas as estimações, ao passo que os coeficientes de Multas $_{t-1}$ são significativos nas três últimas regressões da Tabela 5 (FE 2, FE 3 e FE 4) e no modelo completo da Tabela 6 (FE 4). 
Estes resultados reforçam a hipótese de que a reputação do regulador é um fator importante para reduzir violações ambientais. Além disso, todos os sinais das demais variáveis são condizentes com a literatura e se mantém nos quatro modelos de ambas as tabelas (executando-se a Tx Urbanização).

A principal diferença entre as regressões da Tabela 5 e da Tabela 6 está na variável Gasto Controle $t_{t-1}$ que se tornou significativa quando utilizamos o critério de região para vizinhança. Apesar disso, o impacto da variável é pequeno em todas as metodologias utilizadas. Outro resultado relevante é que a presença de ONGs ambientais não se mostra significativa para conter infrações contra a flora.

Outra diferença refere-se aos valores dos coeficientes estimados. Pelos coeficientes (elasticidades parciais) das variáveis Multas $t_{t-1}$ e Multas $_{t-2}$ no modelo FE 4 para vizinhos fronteiriços (Tabela 5), $\beta_{1}$ e $\beta_{2}$ respectivamente, temos que um aumento de $1 \%$ no valor das multas aplicadas dentro do estado reduz em aproximadamente $0,12 \%$ e $0,16 \%$ a incidência de autos de infração. Para Multas Vizinhos $F_{t-1}$, este impacto é de $0,16 \%(\varphi)$. Para os vizinhos regionais, estes impactos são de $0,10 \%\left(\beta_{1}\right), 0,18 \%\left(\beta_{2}\right)$ e $0,14 \%(\varphi)$, respectivamente.

Estas variáveis captam o efeito específico e o efeito spillover da reputação do regulador. Esses resultados são importantes porque demonstram que uma multa aplicada em um estado aumenta a credibilidade da autoridade ambiental no próprio estado e em todos os vizinhos (fronteiriços ou regionais), amplificando o impacto da multa. Assim, considerar somente as sanções aplicadas dentro do próprio estado pode subestimar o efeito que as multas têm sobre a ocorrência de novas violações ambientais.

Quanto à magnitude dos coeficientes estimados, chama a atenção o fato de que o efeito das multas aplicadas no estado em $t-2$ (coeficiente $\beta_{2}$ ) tenha um efeito impeditivo maior do que as multas aplicadas no período imediatamente anterior (coeficiente $\beta_{1}$ ).

Uma possível explicação é que a possibilidade de recorrer do auto de infração junto aos órgãos ambientais na esfera administrativa (tribunais administrativos), em suas diversas instâncias, e na esfera criminal (tribunais criminais), se a infração também constituir crime, pode postergar a decisão judicial e o cumprimento das penas 
impostas. ${ }^{20}$ Assim, ainda dentro do campo especulativo, podemos entender que os resultados encontrados captam, além da história do regulador em aplicar sanções, o atraso no pagamento das multas. $\mathrm{Ou}$ seja, a possibilidade de recurso e de postergar o pagamento poderia, então, puxar para baixo os coeficientes (principalmente $\beta_{1}$ ), reduzindo o impacto das multas aplicadas no estado.

Em relação às multas aplicadas em estados vizinhos, especulamos que este efeito é provavelmente reduzido (ainda que possivelmente existente), uma vez que é mais difícil para os agentes obterem informações quanto a julgamentos e recursos de outros estados. Assim, o coeficiente $\varphi$ refletiria a disposição da autoridade ambiental em aplicar sanções e fazer cumprir a lei, isto é, especulamos que o que os agentes observam de fato são as multas impostas pelo regulador e não ocorrência de recursos. Não é estranho, portanto, que o coeficiente $\varphi$ tenha uma influência igual ao coeficiente $\beta_{2}$ (no caso dos vizinhos fronteiriços). Shimshack \& Ward (2005), por exemplo, observaram que o efeito impeditivo de uma multa aplicada sobre outras firmas é igual à própria firma ser multada, isto é, o efeito específico e o efeito spillover têm a mesma influência sobre a decisão da firma em cometer infrações.

Para a variável Gasto Controle, que reflete a disposição do regulador em descobrir infrações ambientais, nenhum dos coeficientes estimados se mostrou significativo para as estimações com vizinhos fronteiriços (Tabela 5). Já nas estimações considerando vizinhos regionais os coeficientes são significativos nos três últimos modelos da Tabela 6 (FE 2, FE 3 e FE 4), apesar de apresentaram um impacto diminuto sobre as infrações contra flora. Imaginamos que tal resultado pode refletir o fato de que este tipo de gasto é muito pequeno na maior parte dos estados, não chegando a $1 \%$ do total de despesas. Além disso, não é possível saber em que o dinheiro é efetivamente aplicado (se em máquinas, equipamentos ou gasto em recursos humanos). Para estudos posteriores sugerimos adicionar outras variáveis, tais como o número de postos ou de agentes do IBAMA em cada estado (se estas estiverem disponíveis). ${ }^{21}$

20 Conforme exposto nas seções III (Da Defesa), IV (Da Instrução e Julgamento) e V (Dos Recursos) do Decreto 6.514, o pagamento da multa fica suspenso até a decisão judicial final. Ver também o Decreto 3.179 e a Lei 9.605 (Lei de Crimes Ambientais).

${ }^{21}$ Estes dados foram solicitados ao MMA/IBAMA, mas nos foi informado que estas informações não estão disponíveis porque o MMA/IBAMA não mantém esse tipo de controle por estado, apenas nacionalmente. 
As ONGs ambientais em atuação também não se mostram significativas na análise, em nenhum dos métodos empregados, apesar do sinal ser condizente ao modelo. Ferraz e Seroa da Motta (2002) argumentam que, no Brasil, as ONGs têm um impacto indireto sobre as firmas, através de reclamações aos órgãos reguladores, explicando a quantidade de advertências recebidas e não as infrações diretamente.

Já a variável Tx Urbanização apresentou sinal contrário ao esperado, sugerindo uma relação positiva entre infrações e urbanização. Há duas razões para isto. Em primeiro lugar, a taxa de urbanização pode estar correlacionada ao PIB per capita, em segundo lugar, esta variável pode captar a relação entre taxa de urbanização e infrações descobertas. ${ }^{22}$ Esta última é uma situação bastante comum nas análises de economia do crime, já que os crimes registrados (autos de infração) não correspondem ao conjunto total de crimes (devido ao subregistro de infrações).

Outros resultados importantes se referem à variável Conciência Ambiental, que apresenta sinal negativo e é significativa a $10 \%$, e às variáveis $P I B p c$ e $P I B p c^{2}$, ambas significativas a $5 \%$ e apresentado os sinais esperados (modelos FE 4). Estes resultados sugerem que as estimações que buscam determinar os componentes das infrações ambientais devem considerar as características socioeconômicas das comunidades em suas análises. Quanto ao coeficiente da variável Legislação, que apresenta sinal negativo e significativo, este demonstra que o maior rigor da legislação pode ter provocado um decréscimo de aproximadamente $18 \%$ a $24 \%$, dependendo do critério de vizinhança adotado, na incidência de infrações contra a flora no período após a mudança na lei. Entretanto, uma consideração importante a ser feita é que exatamente nesse período ocorreu uma crise financeira em âmbito mundial. Deste modo, esta variável pode estar refletindo, adicionalmente, os efeitos da crise no Brasil.

\footnotetext{
${ }^{22}$ Nas nossas hipóteses quanto às variáveis explicativas descrevemos que a taxa de urbanização serve como proxy para o papel das comunidades em monitorar e delatar infrações ambientais, isto é, quanto maior a taxa de urbanização, maior é a facilidade em monitorar o comportamento das firmas e em informar as suas ações para a autoridade ambiental.
} 


\section{Considerações Finais}

Nosso objetivo consistiu em testar o papel da regulação no combate a violações ambientais no Brasil. As principais variáveis explicativas referem-se a multas lavradas sobre o estado (efeito específico) e sobre estados vizinhos (efeito spillover), que refletem a reputação do regulador, isto é, uma multa aplicada sinaliza de forma crível a disposição da autoridade ambiental em aplicar multas em outros estados, amplificando o impacto desse tipo de sanção. Os resultados encontrados demonstram que as multas são significativas para conter infrações e que o efeito de um aumento no valor das multas aplicadas em um estado e em seus vizinhos gera uma redução no número de autos de infração para o ano subsequente à aplicação da multa. Assim, a conclusão principal deste trabalho é que focar somente no efeito impeditivo específico pode subestimar a eficácia das multas como sanções e como forma de prevenção para violações ambientais futuras.

Além de testar a influência da reputação do regulador sobre a incidência de infrações ambientais, nós incluímos na análise o papel complementar dos agentes privados. Estas variáveis mostram que as preferências da população quanto ao meio ambiente podem influenciar a incidência de infrações ambientais. Os resultados sugerem que as estimações que buscam determinar os componentes das violações ambientais devem considerar as características socioeconômicas e institucionais das comunidades.

Assim, as análises realizadas geram novas evidências para a efetividade das políticas públicas ambientais no Brasil, principalmente no que se refere às multas aplicadas, e para o papel da população no combate a infrações ambientais. Na medida em que outras variáveis tornarem-se disponíveis, como, por exemplo, quanto à fiscalização ambiental em cada estado (número de agentes ou de postos do IBAMA), novas estimações poderão ser feitas, aprimorando os resultados encontrados. 


\section{Referências}

AFSAH, S.; LAPLANTE, B.; WHEELER, D. Controlling industrial pollution: A new paradigm. Policy research working papers. Washington, DC: World Bank, 1996.

ALMER, C.; GOESCHL, T. Environmental crime and punishment: empirical evidence from the German penal code. Land Economics, 86(4), pg. 707-726, 2010.

ANTON, W. R. Q.; DELTAS, G.; KHANNA, M. Incentives for environmental self-regulation and implications for environmental performance. Journal of Environmental Economics and Management, 48, pg. 632-654, 2004.

BECKER, G. S. Crime and punishment: An economic approach. Journal of Political Economy, 76 (2) pg. 169-217, 1968.

BRASIL. Decreto no 3.179, de 21 de setembro de 1999. Disponível em: < https:/www.planalto.gov.br/ ccivil_03/decreto/D3179.htm>.

BRASIL. Decreto $n^{0}$ 6.514, de 22 de julho de 2008. Disponível em: <https:/www.planalto.gov.br/ ccivil 03/ ato2007-2010/2008/decreto/d6514.htm>.

COHEN, M. A. Empirical Research on the Deterrent Effect of Environmental Monitoring and Enforcement. The Environmental Law Reporter, 30, pg. 10245-10252, 2000.

CHOMITZ, K.; GRAY, D. Roads, Land Use, and Deforestation: A Spatial Model Applied to Belize. World Bank Economic Review, 10(3), pg.487-512, 1996.

CHOMITZ, K. M.; THOMAS, T. S. Determinants of Land Use in Amazônia: A fine-scale Spatial Analysis. American Journal of Agricultural Economics, vol. 85 (4), pg. 1016-1028, 2003.

DASGUPTA, S.; HETTIGE, H.; WHEELER, D. What improves environmental compliance? Evidence from Mexican industry. Journal of Environmental Economics and Management, 39, pg. 39-66, 2000.

EARNHART, D. Regulatory factors shaping environmental performance at publicly-owned treatment plants. Journal of Environmental Economics and Management, 48, pg. 655-681, 2004.

EHRLICH, I. Participation in illegitimate activities: A theoretical and empirical investigation. Journal of Political Economy, 81(3) pg.526-536, 1973.

FERRAZ, C.; SEROA DA MOTTA, R. Regulação, mercado ou pressão social? Os determinantes do investimento ambiental na indústria. Texto para discussão 863. Rio de Janeiro: IPEA, 2002.

GRAY, W.; DEILY, M. Compliance and enforcement: air pollution regulation in the U.S. steel industry. Journal of Environmental Economics and Management, 31, pg. 96-111, 1996.

GRAY, W.; SHIMSHACK, J.P. The Effectiveness of Environmental Monitoring and Enforcement: A Review of the Empirical Evidence. Review of Environmental Economics and Policy 5 (1), pg. 3-24, 2011.

GROSSMAN, G.M., KRUEGER, A.B. Economic growth and the environment. Quarterly Journal of Economics 110 (2), pg. 353-377, 1995.

HELLAND, E. The enforcement of pollution control laws: inspections, violations, and self-reporting. Review of Economics and Statistics, 80, pg. 141-153, 1998.

LAPLANTE, B.; RILSTONE, P. Environmental inspections and emissions in the pulp and paper industry in Quebec. Journal of Environmental Economics and Management, 31, pg. 19-36, 1996.

MAGAT, W. A.; VISCUSI, W. K. Effectiveness of the EPA's regulatory enforcements: the case of industrial effluent standards. Journal of Law and Economics, 30, pg. 331-360, 1990.

MARGULIS, S. Causas do Desmatamento na Amazônia Brasileira. Banco Mundial, 2003. 
NADEAU, L. W. EPA effectiveness at reducing the duration of plant-level noncompliance. Journal of Environmental Economics and Management, 34, pg. 54-78, 1997.

NELSON, G.; GEOGHEGAN, J. Modeling Deforestation and Land Use Change: Sparse Data Environments. Agricultural Economics, 27(3), pg. 201-216, 2002.

OLIVEIRA, R. C.; ALMEIDA, E.; FREGUGLIA, R. S.; BARRETO, R. C. S. Desmatamento e Crescimento Econômico no Brasil: uma análise da Curva de Kuznets Ambiental para a Amazônia Legal. Revista de Economia e Sociologia Rural (RESR), vol. 49, nº3, pg. 709-740, 2011.

PFAFF, A. S. P. What Drives Deforestation in the Brazilian Amazon? Journal of Environmental Economics and Management, 37, pg. 26-43, 1999.

PFAFF, A. S. P.; ROBALINO, J.; WALKER, R.; REIS, E.; PERZ, S.; BOHER, C.; ALDRICH, S. Road Investment, Spatial Intensification and Deforestation in the Brazilian Amazon. Journal of Regional Science, 47 (1), pg. 109-123, 2007.

POLINSKY, A.M.; SHAVELL, S. The economic theory of public enforcement of law. Journal of Economic Literature, 38, pg. $45-76,2000$.

POSNER, R. Economic Analysis of Law. Boston: Little, Brown, 1977.

ROUSSEAU, S. The Impact of Sanctions and Inspections on Firm's Environmental Compliance Decisions. Working Paper, 2008. Disponível em: http://papers.ssrn.com/sol3/papers.cfm?abstract_ $\mathrm{id}=1114020$

RUSSELL, C.S.; HARRINGTON, W.; VAUGHAN, W.J. Economic models of monitoring and enforcement: enforcing pollution control laws. Washington, DC: Resources for the Future, 1986.

SAH, R.K. Social osmosis and patterns of crime. Journal of Political Economy, 99, pg. 1272 - 1295, 1991.

SEROA DA MOTTA, R. Analyzing the environmental performance of the Brazilian industrial sector. Ecological Economics, 57, pg. 269-281, 2006.

SHIMSHACK, J. P.; WARD, M. B. Regulator reputation, enforcement, and environmental compliance. Journal of Environmental Economics and Management, 50, pg. 519-540, 2005.

. Enforcement and over-compliance. Journal of Environmental Economics and Management, 55, pg. 90-105, 2008.

Repeat offenders, enforcement, and environmental compliance. Working Paper, Tulane University, 2010.

SIGMAN, H. Midnight Dumping: Public Policies and Illegal Disposal of Used Oil. RAND Journal of Economics, Vol. 29 (1), pg. 157-178, 1998.

STAFFORD, S. L. The effect of punishment on firm compliance with hazardous waste regulation. Journal of Environmental Economics and Management, 44, pg. 290-308, 2002.

. Assessing the effectiveness of state regulation and enforcement of hazardous waste. Journal of Regulatory Economics, 23, pg.24 - 41, 2003.

UHR, D. A. P.; UHR, J. G. Z.; MUELLER, B. Como as ONGs ambientais influenciam a política ambiental brasileira? Revista Brasileira de Economia, 66 (1), pg. 79- 98, 2012.

VILADRICH-GRAU, M.; GROVES, T. The Oil Spill Process: The Effect of Cost Guard Monitoring on Oil Spills. Environmental and Resource Economics, 10, pg. 315-339, 1997. 